\title{
Distribution of Genomic Species and Antimicrobial Susceptibility in Acinetobacters Isolated from Gangjin Bay, Korea
}

\author{
Jae Young $\mathrm{Oh}^{1}$, Yong Wook Jeong ${ }^{2}$, Hyun Soo Joo ${ }^{2}$, Won Seog Chong ${ }^{5}$, Je Chul Lee ${ }^{3}$, \\ Migma Dorji Tamang ${ }^{3}$, Woo Bum Lee ${ }^{4}$ and Jong Chun Park ${ }^{2^{*}}$ \\ ${ }^{1}$ Avian Disease Division, National Veterinary Research and Quarantine Service, Anyang, Gyeonggi-Do, Korea \\ ${ }^{2}$ Department of Microbiology, School of Medicine, Seonam University, Namwon, Chonbuk, Korea \\ ${ }^{3}$ Department of Microbiology, Kyungpook National University School of Medicine, Daegu, Korea \\ ${ }^{4}$ Department of Civil and Environmental Engineering, Chonnam National University, Gwangju, Korea \\ ${ }^{5}$ Department of Pharmacology, School of Medicine, Seonam University, Namwon, Chonbuk, Korea
}

\begin{abstract}
A total of 90 Acinetobacter isolates from freshwater and seawater in Gangjin Bay of Korea was investigated for the distribution of genomic species, antimicrobial resistance patterns and clonal relatedness. By amplified ribosomal DNA restriction analysis, eighty-nine Acinetobacter isolates were classified into 11 Acinetobacter genomic species. A. johnsonii $(\mathrm{n}=23)$ was the most prevalent, followed by A. baumannii $(\mathrm{n}=13)$, A. calcoaceticus $(\mathrm{n}=13)$, Acinetobacter genomic species $11(\mathrm{n}=10)$, A. phenon 6/ct13TU ( $\mathrm{n}=9)$, A. junii $(\mathrm{n}=5)$, A. venetianus $(\mathrm{n}=5)$, Acinetobacter genomic species 17 $(\mathrm{n}=4)$, 14BJ $(\mathrm{n}=3)$, A. phenon 10/1271 $(\mathrm{n}=2)$, Acinetobacter genomic species $3(\mathrm{n}=1)$, and ungrouped $(\mathrm{n}=1)$. The majority of Acinetobacter genomic species were isolated from the site $\mathrm{A}$ and $\mathrm{B}$, and some known nosocomial pathogens in the clinical environment were observed among them. Of the 11 antimicrobial drugs tested, several A. johnsonii isolates exhibited high-frequency resistance to a wide variety of antimicrobial agents, including ampicillin-sulbactam, piperacillin, ceftazidime, cefotaxime, and sulfamethoxazole $(p<0.001)$. Some Acinetobacter genomic species were resistant to currently used antibiotics but all isolates were susceptible to imipenem, amikacin, and tetracycline. Based on the results of antimicrobial resistance pattern and phylogenetic analysis, 23 A. johnsonii isolates were classified into 19 pulsotypes. In conclusion, there was a significant difference in the distribution of Acinetobacter species between freshwater and seawater. Predominance of A. johnsonii strains was probably due to their ability to proliferate in the contaminated aquatic environment originated from local geographic features. Therefore, the waste effluent from animals and humans plays an important role in the distribution of Acinetobacter species in aquatic environment.
\end{abstract}

Key Words: Acinetobacter johnsonii, High-frequency resistance, Aquatic environment

\section{INTRODUCTION}

The genus Acinetobacter is aerobic Gram-negative nonfermentative cocobacilli that are ubiquitously distributed in

Received: August 10, 2009/ Revised: September 15, 2009

Accepted: September 23, 2009

* Corresponding author: Jong Chun Park. Department of Microbiology, School of Medicine, Seonam University, Namwon, Chonbuk, 590-711, Korea.

Phone: +82-63-620-0340, Fax: +82-63-620-0345,

e-mail: pjcoli@hanmail.net environment, including soil, water, and sewage (1). In the past, these microorganisms were not highlighted in clinical setting, because they were considered to be a normal flora of skin or saprophytes in hospital environment. However, Acinetobacter species have emerged as important opportunistic pathogens in healthcare institutions due to the high prevalence in clinical specimens, occurrence of outbreaks by some Acinetobacter species, and its tendency to acquire multi-drug resistance (MDR) (2 4). In conjunction with its clinical importance, a systematic study for acinetobacters is 
needed to determine natural habitats, species distribution, and antimicrobial susceptibility in ecosystem.

Species identification of acinetobacters is essential to investigate the epidemiology of clinical isolates and to understand the natural occurrence of environmental isolates. Genus level of Acinetobacter can be presumptively identified by phenotypic markers, but the recent taxonomy of Acinetobacter species is based on the genotypic identification. Species identification of Acinetobacter is primarily based on DNA-DNA hybridization, but this method is laborious and is only available in a few reference laboratories (5). Many molecular methods, including amplified ribosomal DNA restriction analysis (ARDRA), amplified fragment length polymorphism, ribotyping, tRNA spacer fingerprinting, and sequence analysis of 16S $23 \mathrm{~S}$ rRNA gene spacer region, have been developed for the identification of Acinetobacter genomic species (2, 4, 6, 7). Until now, 31 Acinetobacter genomic species were delineated, which were composed of 18 named and 13 unnamed species (8). Among them, A. baumannii, Acinetobacter genomic species 3 and Acinetobacter genomic species 13TU, are the most frequently isolated from clinical specimens, whereas $A$. calcoaceticus, A. johnsonii, and Acinetobacter genomic species 11 are frequently found in soil and surface water. Acinetobacter isolates were heavily found in freshwater ( $>$ $\left.10^{4} / 100 \mathrm{ml}\right)$ and raw sewage $\left(10^{6} / 100 \mathrm{ml}\right)(9)$, but the distribution of Acinetobacter species in freshwater and seawater from shoreline was not fully determined by the current taxonomy.

In addition to their unique distribution in animate and inanimate environment, Acinetobacter species have become resistant to various classes of antimicrobial agents through mutation and selection, or by acquiring from other bacteria the genetic mechanism that encodes resistance. Most of clinical Acinetobacter isolates were MDR to clinically available antimicrobial agents, including penicillins/ $\beta$-lactamase inhibitors, cephalosporins, aminoglycosides, fluoroquinolones and carbapenems $(10,11)$. Acinetobacter isolates from natural environment were also resistant to naturally occurring or synthetic antimicrobial agents (12). Drug-resistant acinetobacters in aquatic environment would directly originate from animate environment or susceptible environmental bacteria could acquire resistance genes through horizontal gene transfer $(13,14)$. Aquatic environment has been known to be a reservoir for spreading of antimicrobial resistance by natural transformation or conjugation (15). This study was done to investigate the distribution of genomic species and antimicrobial susceptibility in Acinetobacter isolates from aquatic environment in Gangjin Bay, Korea. The clonal relatedness of the most predominant $A$. johnsonii isolates was also determined.

\section{MATERIALS AND METHODS}

\section{Water sampling}

The water was sampled from the Gangjin Bay, located in the southern extremity of Korea, for two times every spring season during 2004 and 2005. Four sampling sites were selected. Site A is influenced by freshwater inflowing from Tamjin River. Site B is influenced by a small quantity of seawater by the tidal currents. Sites $\mathrm{C}$ and $\mathrm{D}$ are influenced by the ocean currents, but site $\mathrm{D}$ is more seaside than site $\mathrm{C}$. The majority of the inhabitants living in surrounding area of the Gangjin Bay raise livestock such as cows, pigs and poultry, and the waste effluent flows into site A.

The water samples were collected in a sterile bottle at a high tide from the shoreline of the Bay. To culture bacteria, water samples were filtered through a $0.7 \mu \mathrm{m}$ nylon net (Falcon Cell Strainer, BD Biosciences, San Jose, CA, USA) to remove any impurities and then filtered through a membrane filter with a pore size of $0.45 \mu \mathrm{m}$ (Millipore Co., Milford, MA, USA). The filtered membranes were then laid onto an enrichment medium for Acinetobacter species $\left(0.15 \% \mathrm{KH}_{2} \mathrm{PO}_{4}, 1.65 \% \mathrm{Na}_{2} \mathrm{HPO}_{4} \cdot 2 \mathrm{H}_{2} \mathrm{O}, 0.00005 \% \mathrm{FeSO}_{4}\right.$ $\cdot 7 \mathrm{H}_{2} \mathrm{O}, 0.02 \% \mathrm{MgSO}_{4} \cdot 7 \mathrm{H}_{2} \mathrm{O}, 0.01 \% \mathrm{CaCl}_{2}$ and $0.2 \%$ $\left.\mathrm{C}_{2} \mathrm{H}_{3} \mathrm{O}_{2} \mathrm{Na}, \mathrm{pH}, 7.5\right)$ and incubated at $30^{\circ} \mathrm{C}$ for $48 \mathrm{~h}(9,16)$. A well-isolated colony was subcultured onto a MacConkey agar plate (Difco Laboratories, Detroit, MI, USA) using a toothpick.

\section{Physicochemical test of sampling water}

Physicochemical parameters from the four sampling 
sites were directly measured in the field. The ambient water temperature (Digital thermometer, IBRD YSI Model 58, Springfield, NJ, USA), pH (Orion EA 940, Beverly, MA, USA), salinity (Salinity meter, IBRD YSI Model 33) and the nutritional salts for nitrogen-nitrate $\left(\mathrm{NO}_{3}-\mathrm{N}\right)$ and phosphate phosphorus $\left(\mathrm{PO}_{4}-\mathrm{P}\right)$ were analyzed.

\section{Identification of Acinetobacter genomic species}

Acinetobacter genomic species was identified by previously described ARDRA method (2). After amplification of $16 \mathrm{~S}$ ribosomal DNA region by PCR, $10 \mu \mathrm{l}$ of each PCR product was digested for $2 \mathrm{~h}$ at $37^{\circ} \mathrm{C}$ in $20 \mu$ volumes of commercially supplied incubation buffer containing $5 \mathrm{U}$ of respective restriction enzyme AluI, CfoI, $M b o I$, MspI, and RsaI (Roche Diagnostics GmbH, Mannheim, Germany). Restriction fragments were separated by agarose gel electrophoresis in $0.5 \times$ TBE buffer and visualized after being stained with ethidium bromide.

\section{Growth of Acinetobacter species by different salt concentration}

The growth rates of five Acinetobacter species were investigated under various salinity conditions. One milliliter of mid-logarithmic culture adjusted to optical density (OD) 1 at $600 \mathrm{~nm}$ was added to the $250 \mathrm{ml}$ triangle flask containing $100 \mathrm{ml}$ enrichment medium with $1 \%, 2 \%$ and $3 \%(\mathrm{w} / \mathrm{v})$ of sodium chloride, respectively, and then shaken vigorously for $48 \mathrm{~h}$ at $30^{\circ} \mathrm{C}$. The $\mathrm{OD}$ value of each culture was measured every $6 \mathrm{~h}$.

\section{Antimicrobial susceptibility testing}

Antimicrobial susceptibility test was performed using the agar plate method according to the guidelines of the Clinical and Laboratory Standards Institute (CLSI) (17). A fixed concentration of antimicrobial agents was incorporated into the Mueller Hinton agar (Difco Laboratories). Escherichia coli ATCC 25922 and Pseudomonas aeruginosa ATCC 27853 were used as quality control strains. The antimicrobial agents for MIC test were as follows: ampicillin-sulbactam (Sigma Chemical Co., St. Louis, MO, USA), piperacillin (ICN Biomedicals, Irvine, Ca, USA), ceftazidime (Sigma
Chemical Co.), cefotaxime (DUCHEFA, Haarlem, Netherland), imipenem (Sigma Chemical Co.), colistin (Sigma Chemical Co.), amikacin (ICN Biomedicals), gentamicin (DUCHEFA), tetracycline (Sigma Chemical Co.), ciprofloxacin (Fluka, Buchs, Switzerland), sulfamethoxazole (Sigma Chemical Co.).

\section{Pulsed-field gel electrophoresis (PFGE)}

The PFGE plugs were prepared according to a modified version of the Gautom method (18) and the genomic DNA was digested with ApaI (Roche Diagnostics $\mathrm{GmbH}$ ) for $20 \mathrm{~h}$ and separated on a 1\% agarose gel using a contourclamped homogeneous apparatus (CHEF DRIII systems; Bio-Rad Co, Hercules, CA, USA). The agarose plugs were digested with $50 \mathrm{U}$ of $\mathrm{ApaI}$ at $37^{\circ} \mathrm{C}$ for $24 \mathrm{~h}$. A lambda ladder comprising 48.5-kb concatemers (Roche Diagnostics $\mathrm{GmbH})$ was used as size standards. The agarose gels were run in $0.5 \times \mathrm{TBE}$ buffer at $14^{\circ} \mathrm{C}$ at $6 \mathrm{~V} / \mathrm{cm}$ for $19 \mathrm{~h}$ with a pulse time 5 to $20 \mathrm{~s}$ with a linear ramp. The gel images were stored electronically as TIFF files and analyzed using GelCompar II computer program (Applied Maths Co., Sine-Martens-Latem, Belgium) for band analysis with the Dice coefficient used to compute the similarity matrix and then transformed with the arithmetic average (UPGMA).

\section{Statistical analysis}

The statistical analysis was done with SPSS version 11.5 for Microsoft windows. The statistical significance of difference between groups was analyzed by Student's t-test and $\chi^{2}$ test.

\section{RESULTS}

\section{Physiochemical characterization of survey water}

The physicochemical parameters of sampling waters were summarized in Table 1. There was no significant difference in water temperature among the sampling sites. The $\mathrm{pH}$ and salinity of sites C and D showed a typical seawater, whereas site A was influenced by freshwater and site B was a crossing point between freshwater and seawater. The total nitrogen and phosphate phosphorus were significantly higher 
Table 1. Physicochemical characteristics of sampled water at survey sites

\begin{tabular}{lccccc}
\hline \hline \multirow{2}{*}{ Item } & & \multicolumn{4}{c}{ Survey site } \\
\cline { 3 - 6 } & & Site A & Site B & Site C & Site D \\
\hline Temperature $\left({ }^{\circ} \mathrm{C}\right)$ & 2004 & 16.6 & 15.9 & 15.3 & 15.1 \\
& 2005 & 16.7 & 16.1 & 16.4 & 15.5 \\
$\mathrm{pH}$ & 2004 & 7.3 & 7.9 & 8.1 & 8.1 \\
& 2005 & 7.4 & 7.9 & 8.1 & 7.9 \\
Salinity $(\%)$ & 2004 & 8.9 & 24.8 & 31.8 & 32.3 \\
& 2005 & 14.1 & 21.8 & 27.5 & 28.4 \\
Total nitrogen (mg/L) & 2004 & 0.872 & 0.356 & 0.164 & 0.142 \\
& 2005 & 1.059 & 0.352 & 0.178 & 0.171 \\
Phosphate phosphorus & 2004 & 0.064 & 0.037 & 0.019 & 0.013 \\
(mg/L) & 2005 & 0.058 & 0.028 & 0.014 & 0.017 \\
\hline
\end{tabular}

at site A than the other sampling sites due to the waste effluent from farms and villages.

\section{Distribution of Acinetobacter genomic species}

A total of 90 Acinetobacter isolates were obtained from four sampling sites. Forty-eight $(53.3 \%)$ isolates were obtained from freshwater, $31(34.4 \%)$ isolates were from crossing point between the freshwater and the seawater and $11(12.2 \%)$ isolates were found in seawater (Table 2). Of the 90 Acinetobacter isolates, 89 isolates were classified into 11 Acinetobacter genomic species. Genomic species of one Acinetobacter isolate from site B was not determined by ARDRA. Overall, A. johnsonii (n=23) was the most prevalent, followed by A. baumannii ( $\mathrm{n}=13)$, A. calcoaceticus $(\mathrm{n}=13)$, and $A$. phenon $6 \mathrm{ct} / 13 \mathrm{TU}(\mathrm{n}=9)$, which were all predominant species at sites $\mathrm{A}$ and $\mathrm{B}$. There was a great difference in the distribution of Acinetobacter species between the sampling sites. A. junii and Acinetobacter genomic species 10 were only found in freshwater, whereas Acinetobacter genomic species 17 were isolated from seawater.

To determine whether the unique distribution of Acinetobacter species in freshwater and seawater was influenced by the salinity of the sampled water, five Acinetobacter species were cultured in the medium supplemented with
Table 2. Distribution of Acinetobacter genomic species in Gangjin Bay in Korea

\begin{tabular}{lrrrrc}
\hline \multirow{2}{*}{ Genomic species } & \multicolumn{5}{c}{ No. of isolates from sites } \\
\cline { 2 - 6 } & A & B & C & D & Total \\
\hline A. johnsonii & 14 & 9 & 0 & 0 & 23 \\
A. calcoaceticus & 8 & 4 & 0 & 1 & 13 \\
A. baumannii & 7 & 5 & 0 & 1 & 13 \\
11 & 2 & 8 & 0 & 0 & 10 \\
A. phenon 6/ct13TU & 8 & 1 & 0 & 0 & 9 \\
A. junii & 6 & 0 & 0 & 0 & 6 \\
A. venetianus & 0 & 2 & 2 & 1 & 5 \\
17 & 0 & 0 & 3 & 1 & 4 \\
14BJ & 1 & 0 & 2 & 0 & 3 \\
A. phenon 10/1271 & 2 & 0 & 0 & 0 & 2 \\
3 & 0 & 1 & 0 & 0 & 1 \\
Ungrouped & 0 & 1 & 0 & 0 & 1 \\
\hline \multicolumn{1}{c}{ Total } & 48 & 31 & 7 & 4 & 90 \\
\hline
\end{tabular}

$1 \%, 2 \%$ and $3 \%$ salinity, and the optical density of the bacterial growth was measured using a spectrophotometer. Three predominant species at both sites $\mathrm{A}$ and $\mathrm{B}, \mathrm{A}$. calcoaceticus, $A$. baumannii, and $A$. johnsonii, were selected and $A$. venetianus and Acinetobacter genomic species 17, which were predominant at sites $\mathrm{C}$ and $\mathrm{D}$, were selected. The growth of all Acinetobacter species tested slightly decreased with the increasing of salinity, but there was no significant difference in the growth rates of each Acinetobacter species under the different salinities. However, three predominant Acinetobacter species at sites A and B displayed higher growth rate than two selected Acinetobacter species at sites $\mathrm{C}$ and $\mathrm{D}$ under $1 \%$ and $2 \%$ salinity condition.

Antimicrobial susceptibility of aquatic Acinetobacter isolates

The MICs of 11 antimicrobial agents against all 90 Acinetobacter isolates were determined by agar dilution method. Antimicrobial resistance patterns, MICs, and resistance percentages are presented in Table 3. Four (4.4\%) A. johnsonii of all Acinetobacter isolates were only 
Table 3. MICs and the percentages of resistance (\%R) of 90 Acinetobacter isolates from Gangjin Bay of Korea

\begin{tabular}{|c|c|c|c|c|c|c|c|c|c|c|c|}
\hline \multirow{2}{*}{$\begin{array}{l}\text { Acinetobacter genomic } \\
\text { species }(n=90)\end{array}$} & \multicolumn{11}{|c|}{$\mathrm{MIC}_{90}$ and $\% \mathrm{R}$ of ${ }^{\mathrm{a}}$} \\
\hline & $\mathrm{AMS}^{\mathrm{b}}$ & PIP & CAZ & CTX & IP & $\mathrm{CS}$ & GM & AMK & CIP & TET & SMX \\
\hline A. johnsonii $(\mathrm{n}=23)$ & $\begin{array}{c}>128 / \\
4.4\end{array}$ & $\begin{array}{l}\geq 512 / \\
5.6\end{array}$ & $\begin{array}{l}128 / \\
10.0\end{array}$ & $\begin{array}{l}128 / \\
4.4\end{array}$ & $<1 / 0$ & $<1 / 0$ & $<4 / 1.1$ & $2 / 0$ & $0.5 / 2.2$ & $4 / 0$ & $\begin{array}{c}\geq 1,024 / \\
7.8\end{array}$ \\
\hline A. calcoaceticus $(\mathrm{n}=13)$ & $4 / 0$ & $\geq 512 / 2.2$ & $4 / 1.1$ & $16 / 0$ & $<1 / 0$ & $<1 / 0$ & $<4 / 0$ & $4 / 0$ & $<0.25 / 0$ & $2 / 0$ & $32 / 0$ \\
\hline A. baumannii $(\mathrm{n}=13)$ & $4 / 0$ & $\geq 512 / 2.2$ & $8 / 0$ & $16 / 0$ & $<1 / 0$ & $4 / 0$ & $<4 / 0$ & $8 / 0$ & $<0.25 / 0$ & $4 / 0$ & $16 / 0$ \\
\hline $11(n=10)$ & $2 / 0$ & $64 / 1.1$ & $8 / 1.1$ & $16 / 0$ & $<1 / 0$ & $8 / 5.6$ & $<4 / 0$ & $4 / 0$ & $8 / 4.4$ & $4 / 0$ & $16 / 0$ \\
\hline A. phenon 6ct:13TU (n=9) & $4 / 0$ & $\geq 512 / 3.3$ & $8 / 0$ & $16 / 0$ & $<1 / 0$ & $<1 / 0$ & $<4 / 0$ & $4 / 0$ & $<0.25 / 0$ & $2 / 0$ & $<8 / 0$ \\
\hline A. junii $(\mathrm{n}=6)$ & $<0.5 / 0$ & $32 / 1.1$ & $4 / 0$ & $8 / 0$ & $4 / 0$ & $8 / 3.3$ & $<4 / 0$ & $4 / 0$ & $0.5 / 0$ & $4 / 0$ & $64 / 1.1$ \\
\hline A. venetianus $(\mathrm{n}=5)$ & $<0.5 / 0$ & $16 / 0$ & $4 / 0$ & $8 / 0$ & $<1 / 0$ & $4 / 0$ & $<4 / 0$ & $8 / 0$ & $<0.25 / 0$ & $2 / 0$ & $<8 / 0$ \\
\hline $17(n=4)$ & $2 / 0$ & $8 / 0$ & $<2 / 0$ & $<2 / 0$ & $<1 / 0$ & $4 / 0$ & $<4 / 0$ & $2 / 0$ & $<0.25 / 0$ & $4 / 0$ & $16 / 0$ \\
\hline $14 \mathrm{BJ}(\mathrm{n}=3)$ & $2 / 0$ & $32 / 0$ & $8 / 0$ & $16 / 0$ & $<1 / 0$ & $4 / 0$ & $<4 / 0$ & $4 / 0$ & $8 / 1.1$ & $2 / 0$ & $<8 / 0$ \\
\hline A. phenon $10 / 1271(n=2)$ & $4 / 0$ & $8 / 0$ & $<2 / 0$ & $4 / 0$ & $<1 / 0$ & $<1 / 0$ & $<4 / 0$ & $4 / 0$ & $<0.25 / 0$ & $2 / 0$ & $<8 / 0$ \\
\hline $3(n=1)$ & $1 / 0$ & $32 / 0$ & $4 / 0$ & $16 / 0$ & $<1 / 0$ & $<1 / 0$ & $<4 / 0$ & $2 / 0$ & $<0.25 / 0$ & $2 / 0$ & $<8 / 0$ \\
\hline Ungrouped $(\mathrm{n}=1)$ & $4 / 0$ & $<4 / 0$ & $<2 / 0$ & $4 / 0$ & $<1 / 0$ & $8 / 1.1$ & $<4 / 0$ & $2 / 0$ & $<0.25 / 0$ & $4 / 0$ & $<8 / 0$ \\
\hline
\end{tabular}

${ }^{\mathrm{a}}$ AMS, ampicillin-sulbactam (MIC range, 0.5 to $128 \mu \mathrm{g} / \mathrm{ml}$ ); PIP, piperacillin (4 to $512 \mu \mathrm{g} / \mathrm{ml}$ ); CAZ, ceftazidime (2 to $128 \mu \mathrm{g} / \mathrm{ml}$ ); CTX; cefotaxime (2 to $256 \mu \mathrm{g} / \mathrm{ml})$; CS; colistin (1 to $32 \mu \mathrm{g} / \mathrm{ml})$; AMK, amikacin (1 to $64 \mu \mathrm{g} / \mathrm{ml}) ; \mathrm{GM}$, gentamicin (4 to $256 \mu \mathrm{g} / \mathrm{ml})$; TET, tetracycline (1 to $16 \mu \mathrm{g} / \mathrm{ml})$; CIP, ciprofloxacin ( 0.25 to $32 \mu \mathrm{g} / \mathrm{ml})$; SMX, sulfamethoxazole (8 to $1,024 \mu \mathrm{g} / \mathrm{ml}$ ).

${ }^{\mathrm{b}}$ MIC values to sulbactam are omitted

resistant to ampicillin-sulbactam (the MICs for $90 \%$ of the strains tested was $\geq 128 / 64 \mu \mathrm{g} / \mathrm{ml})$. The Acinetobacter genospecies for piperacillin (PIP) with $\mathrm{MIC}_{90}(\geq 512 \mu \mathrm{g} /$ $\mathrm{ml}$ ) were $A$. johnsonii (5.6\%), A. calcoaceticus (2.2\%), A. buamannii (2.2\%), and A. phenon 6ct/13TU (3.3\%). Five (5.6\%) A. johnsonii among the 6 Acinetobacter genomic species resistant to piperacillin showed high resistance rate. Three Acinetobacter genospecies (9 [10.0\%] A. johnsonii, 1 [1.1\%] A. calcoaceticus, and 1 [1.1\%] Acinetobacter genomic species 11) were resistant to ceftazidime and four (4.4\%) A. johnsonii were also resistant to cefotaxime with $\operatorname{MIC}_{90}(128 \mu \mathrm{g} / \mathrm{ml})$ in agreement with ampicillin-sulbactam and ceftazidime MICs tested. Five (5.6\%) Acinetobacter genomic species 11 were resistant to colistin (breakpoint, $\geq 4 \mu \mathrm{g} / \mathrm{ml})$ with $\mathrm{MIC}_{90}(8 \mu \mathrm{g} / \mathrm{ml})$, followed by $3(3.3 \%) A$. junii, and 1 (1.1\%) Ungrouped. Only one (1.1\%) A. johnsonii among all the isolates was resistant to gentamicin $(\geq 256 \mu \mathrm{g} / \mathrm{ml})$. Four (4.4\%) Acinetobacter genomic species 11, 2 (2.2\%) A. johnsonii, and 1 (1.1\%) 14BJ were resistant to ciprofloxacin (breakpoint, $\geq 4 \mu \mathrm{g} / \mathrm{ml}$ ). Especially, the MICs $(16 \mu \mathrm{g} / \mathrm{ml})$ against two A. johnsonii isolates were twofold higher than those with others resistant strains. Seven (7.8\%) A. johnsonii and one (1.1\%) A. junii exhibited a high level of resistance to sulfamethoxazole $\left(\mathrm{MIC}_{90}\right.$, $\geq 1,024 \mu \mathrm{g} / \mathrm{ml}$ ).

\section{Epidemiological relationship of aquatic A. johnsonii} isolates

A total of 23 A. johnsonii isolates were analyzed to determine their clonal relatedness. Thirteen A. johnsonii isolates from site $\mathrm{A}$ were classified into 11 pulsotypes and 10 isolates from site $\mathrm{B}$ were classified into 8 pulsotypes at a similarity value of 0.85 (Fig. 1). Two A. johnsonii isolates of site B showed identical PFGE pattern, but they showed different antimicrobial resistance patterns to several betalactam antibiotics.

\section{DISCUSSION}

In the present study, 90 Acinetobacter strains collected from Gangjin Bay of Korea were investigated for genotypic identity and antibiotic susceptibility under the ecological 


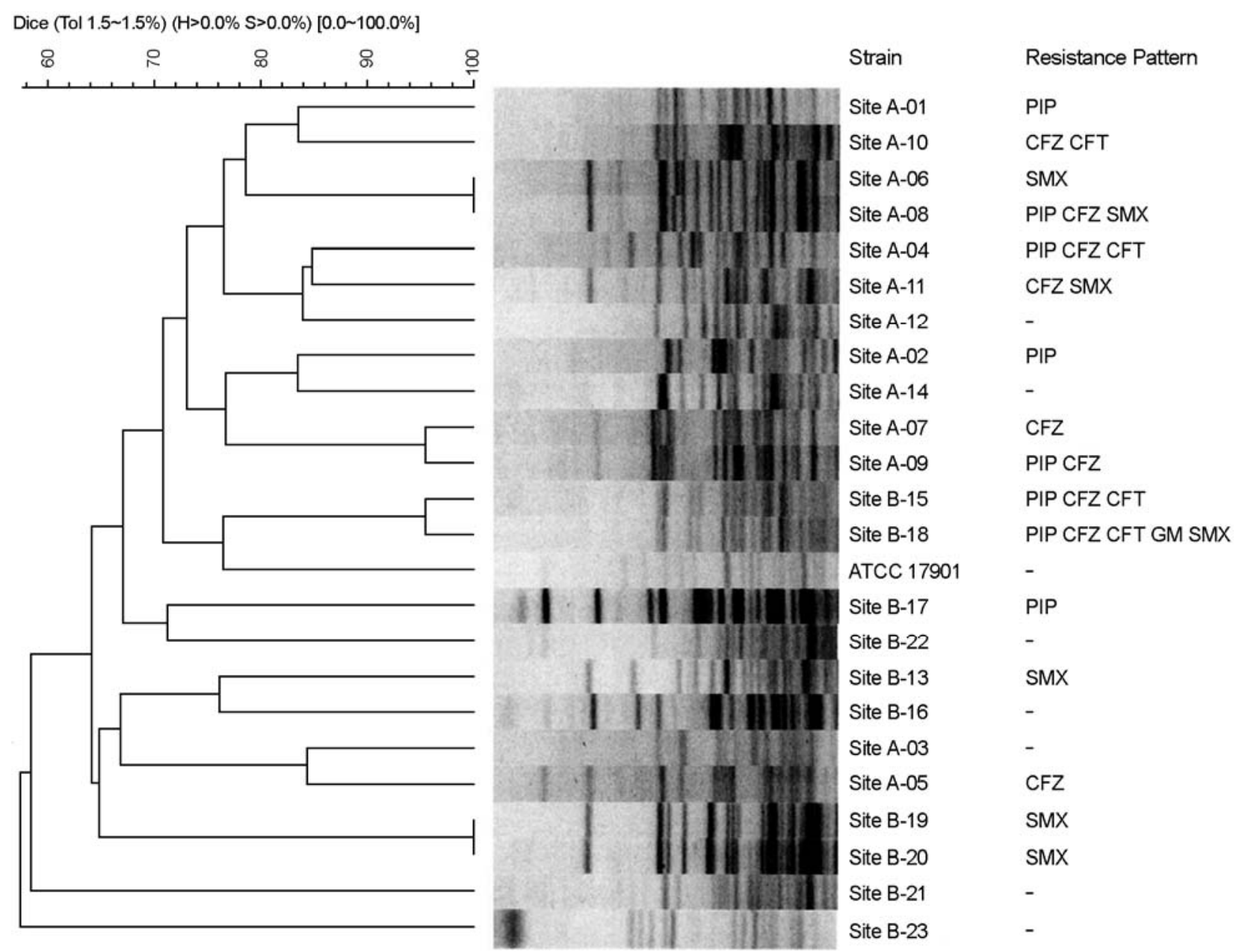

Figure 1. Phylogenetic analysis of 23 A. johnsonii isolates from the Gangjin Bay of Korea. CHEF electrophoresis of ApaI-digested genomic DNAs. The dendrogram is based on cluster analysis by the unweighted-pair group method with average linkages.

condition of sampling sites. Epidemiological typing of predominant A. johnsonii isolates was also analyzed by PFGE. The results of the physiochemical characterization are summarized in Table 1. There was no difference in water temperature. Seveno et al (19) described that bacteria can proliferate more lively in the environmental conditions containing organic sources, solid surface, sediments, and nutrition (phosphate and nitrates) necessary for division of bacteria in aquatic environment. In case of site A, bacterial growth condition seems to be better than other sampling sites with regards to the salinity and total nitrogen and phosphate phosphorus concentrations. Accordingly, site A could display dominant microorganisms originated from freshwater or excreta of humans and animals.
The growth rates of five selected Acinetobacter species were not significantly different under $3 \%$ salinity. These results suggest that the unique distribution of Acinetobacter species between freshwater and seawater could have been influenced by other factors than the salinity. A high prevalence of various Acinetobacter species at site $\mathrm{A}$ is possibly due to the waste effluent from farms and villages.

The distribution of Acinetobacter species in the inanimate environment has been studied and demonstrated that there were some differences in the distribution of Acinetobacter species according to the geographical regions. $A$. calcoaceticus, A. johnsonii, A. haemolyticus, and Acinetobacter genomic species 11 were found most frequently in soil and surface water in Germany (20). Acinetobacter 
isolates were found in 22 of 60 soil samples in Hong Kong and the most frequent species were Acinetobacter genomic species 3 and A. baumannii (21). Berlau et al (22) demonstrated that Acinetobacter isolates were detected in 30 of 177 vegetables from the United Kingdom and that $A$. baumannii and Acinetobacter genomic species 11 were the most predominant species. A. baumannii and Acinetobacter genomic species $13 \mathrm{TU}$ are important hospital-acquired pathogens and are occasionally an etiologic agent of animal infection (21). A. phenon 6/ct13TU strains have been reported from a University hospital of Korea (23) but they do not appear to be a typical environmental species. In this study, A. johnsonii, A. calcoaceticus, A. baumannii, Acinetobacter genomic species 11, and A. phenon 6/ct13TU were found to be the predominant species. Thus, those isolates found at site A and B could have originated from the waste effluent from villages or soil. A. venetianus and Acinetobacter genomic species 17 found at site C and D would be aboriginal microorganisms that survive in seawater rather than freshwater.

The antimicrobial resistance patterns of 90 Acinetobacter isolates were determined. Overall, the Acinetobacter isolates from Gangjin Bay were found to exhibit a moderate level to high frequency of resistance to ampicillin-sulbactam (4.4\%), piperacillin $(15.6 \%)$, ceftazidime $(12.2 \%)$, colistin $(10.0 \%)$, ciprofloxacin $(8.9 \%)$, sulfamethoxazole $(8.9 \%)$, cefotaxime $(7.8 \%)$, and gentamicin $(1.1 \%)$ but all isolates were susceptible to imipenem, amikacin, and tetracycline. Several A. johnsonii isolates exhibited high-frequency resistance to a wide variety of antimicrobial agents, including ampicillin-sulbactam, piperacillin, ceftazidime, cefotaxime, and sulfamethoxazole $(p<0.001)$. A. johnsonii, known as a nosocomial pathogen, considered a commensal on human skin, and that has been rarely reported from the hospitalized patients as well as clinical setting in Korea (24). In addition, antimicrobial resistance patterns against those isolates were not common. As a result, $A$. johnsonii isolates showing MDR patterns different from other Acinetobacter genomic species were probably autochthonous strains living in the survey area.

Interestingly, Acinetobacter genomic species 11 showed a high frequency of resistance to colistin and ciprofloxacin as compared to other Acinetobacter genomic species. Recently, the isolation frequency of MDR A. baumannii strains including carbapenem-resistant have been increased in the clinical setting $(25,26)$. A. baumannii isolates in this study were susceptible to those antibiotics, and had low frequency of resistance, whereas resistance to colistin focused on the Acinetobacter genomic species 11 and $A$. junii than $A$. johnsonii isolates resistant to antimicrobial agents. It is suggested that colistin-resistant Acinetobacter isolates were first found in the aquatic environment of Gangjin Bay, as opposed to that have not yet been reported in the clinical isolates.

Sulfamethoxazole-resistant Acinetobacter isolates in this study demonstrated high-level resistance equal to that shown by enteric gram-negative bacteria or nosocomial organisms isolated from hospital environment. In a previous preliminary study, eight sulfamethoxazole-resistant Acinetobacter isolates from the survey area were examined for sul1 and sul2 gene according to the method described by Park et al (27). As a result, the sul2 gene was only detected in five $A$. johnsonii isolates but the remaining isolates were negative. In addition, class 1 integron including integrase gene as well as sul1 gene also had not been found (data not shown). Studies examining trimethoprim/sulfamethoxazole-resistant Escherichia coli and Stenotrophomonas maltophilia isolates recently reported that some of those isolates possessed sul2 gene carrying large plasmids, whereas others carried sul1 gene on the class 1 integrons $(28,29)$. Thus, it was speculated that would be present resistance determinants encoding sulfamethoxazole in the sul2-positive A. johnsonii isolates.

Acinetobacter isolates from aquatic environment were more susceptible to antimicrobial agents as compared to the MDR gram-negative bacteria in clinical isolates from humans and animals and some Acinetobacter species are intrinsically resistance to $\beta$-lactams, some cephalosporins, and chloramphenicol (30), which are responsible for the prevalence of resistance to these antimicrobial agents in this study. Moreover, aquatic acinetobacters can acquire resistance determinants by the horizontal gene transfer (31). Resistance to folate pathway inhibitors such as trimethoprim 
and sulfamethoxazole was infrequently found in the bacteria from aquatic environment. Since resistance determinants of antifolate agents were usually located in the plasmids of gram-negative bacteria, trimethoprim resistance conferring dihydrofolate reductase genes and various types of sul genes could be transferred to Acinetobacter species in aquatic environment (32). Since a high level of resistance to fluoroquinolones is mediated by chromosomal mutation of DNA gyrases (33), resistance to fluoroquinolones has been known as the critical indicator to reveal inflow of the waste products from animate environment (34). As a result, some of Acinetobacter genomic species resistant to various classes of antimicrobial agents in this study would be supposed to originate from humans or animals, whereas other Acinetobacter isolates susceptible to $\beta$-lactam, $\beta$ lactamase inhibitor, cephalosporins and aminoglycosides, and folate pathway inhibitors were probably autochthonous strains living in the Gangjin Bay. Based on the results of antimicrobial susceptibility and phylogentic analysis, $23 \mathrm{~A}$. johnsonii isolates were classified into 19 plusotypes. The genetic heterogeneity of $A$. johnsonii isolates is possibly due to the influx of new clones from the waste effluent and/or the animate environment. In conclusion, we demonstrated the species distribution and antimicrobial susceptibility patterns of Acinetobacter isolates from aquatic environment of Gangjin Bay. There was a significant difference in the distribution of Acinetobacter species between freshwater and seawater. Interestingly, A. baumannii was found to be one of the predominant species in aquatic environment in Korea, but A. baumannii isolates did not show MDR phenotype, probably suggesting the autochthonous strains in aquatic environment. Moreover, the predominance of $A$. johnsonii isolates was probably due to their ability to proliferate in the aboriginal aquatic environment as well as fecal contamination of animal and human originated from local geographic features. Consequently, the waste effluent from animals and humans plays an important role in the distribution of Acinetobacter species in aquatic environment. Further studies for Acinetobacter species in ecosystem are mandatory to increase our knowledge of the antimicrobial resistance mechanisms and epidemiological relationship of
Acinetobacter species in association with clinical isolates.

\section{REFERENCES}

1) Bergogne-Bérézin E, Towner KJ. Acinetobacter spp. as nosocomial pathogens: microbiological, clinical, and epidemiological features. Clin Microbiol Rev 1996;9: 148-65.

2) Nemec A, De Baere T, Tjernberg I, Vaneechoutte M, van der Reijden TJ, Dijkshoorn L. Acinetobacter ursingii sp. nov. and Acinetobacter schindleri sp. nov., isolated from human clinical specimens. Int J Syst Evol Microbiol 2001;51:1891-9.

3) Oh JY, Kim KS, Jeong YW, Cho JW, Park JC, Lee JC. Epidemiological typing and prevalence of integrons in multiresistant Acinetobacter strains. APMIS 2002;110: 247-52.

4) van Dessel H, Dijkshoorn L, van der Reijden T, Bakker N, Paauw A, van den Broek P, Verhoef J, Brisse S. Identification of a new geographically widespread multiresistant Acinetobacter baumannii clone from European hospitals. Res Microbiol 2004;155:105-12.

5) Tjernberg I, Ursing J. Clinical strains of Acinetobacter classified by DNA-DNA hybridization. APMIS 1989; 97:595-605.

6) Chang HC, Wei YF, Dijkshoorn L, Vaneechoutte M, Tang CT, Chang TC. Species-level identification of isolates of the Acinetobacter calcoaceticusAcinetobacter baumannii complex by sequence analysis of the 16S-23S rRNA gene spacer region. J Clin Microbiol 2005;43:1632-9.

7) Vaneechoutte M, Dijkshoorn L, Tjernberg I, Elaichouni A, de Vos P, Claeys G, Verschraegen G. Identification of Acinetobacter genomic species by amplified ribosomal DNA restriction analysis. J Clin Microbiol 1995; 33:11-5.

8) Ko WC, Lee NY, Su SC, Dijkshoorn L, Vaneechoutte M, Wang LR, Yan JJ, Chang TC. Oligonucleotide arraybased identification of species in the Acinetobacter calcoaceticus-A. baumannii complex in isolates from blood cultures and antimicrobial susceptibility testing of the isolates. J Clin Microbiol 2008;46:2052-9.

9) Lacroix SJ, Cabelli VJ. Membrane filter method for 
enumeration of Acinetobacter calcoaceticus from environmental waters. Appl Environ Microbiol 1982; 43:90-6.

10) Goldstein FW, Labigne-Roussel A, Gerbaud G, Carlier C, Collatz E, Courvalin P. Transferable plasmidmediated antibiotic resistance in Acinetobacter. Plasmid $1983 ; 10: 138-47$.

11) Towner KJ. Clinical Importance and Antibiotic Resistance of Acinetobacter spp. Proceedings of a symposium held on 4 5 November 1996 at Eilat, Israel. J Med Microbiol 1997;46:721-46.

12) Guardabassi L, Dalsgaard A, Olsen JE. Phenotypic characterization and antibiotic resistance of Acinetobacter spp. isolated from aquatic sources. J Appl Microbiol 1999;87:659-67.

13) Hendrickx L, Hausner M, Wuertz S. Natural genetic transformation in monoculture Acinetobacter sp. strain BD413 biofilms. Appl Environ Microbiol 2003;69: 1721-7.

14) Schmidt AS, Bruun MS, Dalsgaard I, Larsen JL. Incidence, distribution, and spread of tetracycline resistance determinants and integron-associated antibiotic resistance genes among motile aeromonads from a fish farming environment. Appl Environ Microbiol 2001;67:5675-82.

15) Nielsen KM, van Weerelt MD, Berg TN, Bones AM, Hagler AN, van Elsas JD. Natural transformation and availability of transforming DNA to Acinetobacter calcoaceticus in soil microcosms. Appl Environ Microbiol 1997;63:1945-52.

16) Baumann P. Isolation of Acinetobacter from soil and water. J Bacteriol 1968;96:39-42.

17) National Committee for Clinical Laboratory Standards: Performance standards for antimicrobial susceptibility testing. Approved standard, 2nd ed. M38-A2. CLSI, Wayne, PA., 2008.

18) Gautom RK. Rapid pulsed-field gel electrophoresis protocol for typing of Escherichia coli O157:H7 and other gram-negative organisms in 1 day. J Clin Microbiol 1997;35:2977-80.

19) Seveno NA, Kallifidas D, Smalla K, van EJD, Collard JM, Karagouni AD, Wellington EMH. Occurrence and reservoirs of antibiotic resistance genes in the environment. Rev Med Microbiol 2002;13:15-27.
20) Seifert H, Dijkshoorn L, Gerner-Smidt P, Pelzer N, Tjernberg I, Vaneechoutte M. Distribution of Acinetobacter species on human skin: comparison of phenotypic and genotypic identification methods. J Clin Microbiol 1997;35:2819-25.

21) Peleg AY, Seifert H, Paterson DL. Acinetobacter baumannii: emergence of a successful pathogen. Clin Microbiol Rev 2008;21:538-82.

22) Berlau J, Aucken HM, Houang E, Pitt TL. Isolation of Acinetobacter spp. including A. baumannii from vegetables: implications for hospital-acquired infections. J Hosp Infect 1999;42:201-4.

23) Lim YM, Shin KS, Kim J. Distinct antimicrobial resistance patterns and antimicrobial resistance harboring genes according to genomic species of Acinetobacter isolates. J Clin Microbiol 2007;45:902-5.

24) Seifert H, Strate A, Schulze A, Pulverer G. Vascular catheter-related bloodstream infection due to Acinetobacter johnsonii (formerly Acinetobacter calcoaceticus var. lwoffi): report of 13 cases. Clin Infect Dis 1993; $17: 632-6$.

25) Gales AC, Jones RN, Sader HS. Global assessment of the antimicrobial activity of polymyxin B against 54 731 clinical isolates of Gram-negative bacilli: report from the SENTRY antimicrobial surveillance programme (2001 2004). Clin Microbiol Infect 2006;12: 315-21.

26) Ko KS, Suh JY, Kwon KT, Jung SI, Park KH, Kang CI, Chung DR, Peck KR, Song JH. High rates of resistance to colistin and polymyxin B in subgroups of Acinetobacter baumannii isolates from Korea. J Antimicrob Chemother 2007;60:1163-7.

27) Park JC, Lee JC, Oh JY, Jeong YW, Cho JW, Joo HS, Lee WK, Lee WB. Antibiotic selective pressure for the maintenance of antibiotic resistant genes in coliform bacteria isolated from the aquatic environment. Water Sci Technol 2003;47:249-53.

28) Infante B, Grape M, Larsson M, Kristiansson C, Pallecchi L, Rossolini GM, Kronvall G. Acquired sulphonamide resistance genes in faecal Escherichia coli from healthy children in Bolivia and Peru. Int J Antimicrob Agents 2005;25:308-12.

29) Toleman MA, Bennett PM, Bennett DM, Jones RN, Walsh TR. Global emergence of trimethoprim/ 
sulfamethoxazole resistance in Stenotrophomonas maltophilia mediated by acquisition of sul genes. Emerg Infect Dis 2007;13:559-65.

30) Gerner-Smidt P, Frederiksen W. Acinetobacter in Denmark: I. Taxonomy, antibiotic susceptibility, and pathogenicity of 112 clinical strains. APMIS 1993;101: 815-25.

31) Guardabassi L, Dijkshoorn L, Collard JM, Olsen JE, Dalsgaard A. Distribution and in-vitro transfer of tetracycline resistance determinants in clinical and aquatic Acinetobacter strains. J Med Microbiol 2000; 49:929-36.

32) Petersen A, Guardabassi L, Dalsgaard A, Olsen JE.
Class I integrons containing a dhfrI trimethoprim resistance gene cassette in aquatic Acinetobacter spp. FEMS Microbiol Lett 2000;182:73-6.

33) De la Fuente CM, Dauros SP, Bello TH, Domínguez YM, Mella MS, Sepúlveda AM, Zemelman ZR, González RG. Mutations in gyrA and gyrB genes among strains of Gram-negative bacilli isolated from Chilean hospitals and their relation with resistance to fluoroquinolones. Rev Med Chil 2007;135:1103-10.

34) Unicomb L, Ferguson J, Riley TV, Collignon P. Fluoroquinolone resistance in Campylobacter absent from isolates, Australia. Emerg Infect Dis 2003;9:1482-3. 